\title{
DESIGN OF LIVESTOCK MANAGEMENT TOOL FOR CLIMATE CHANGE RISK IN MONGOLIA
}

\author{
A. Oba ${ }^{\text {a }}$ W.Yan ${ }^{\text {b }}$ \\ ${ }^{a}$ Graduate School of Media and Governance, Keio University, Endo 5322 Fujisawa Kanagawa, 252-0816, Japan - \\ perry@ @fc.keio.ac.jp \\ ${ }^{\mathrm{b}}$ Faculty of Environment and Information Studies, Keio University, Endo 5322 Fujisawa Kanagawa, 252-0816, Japan - \\ yan@sfc.keio.ac.jp
}

IV/5, IV/1, II/IV, IV/8, IV/3: Free and Open Source Web Mapping and Processing

KEY WORDS: Bayan Sum, Mongolia, WebGIS, Climate Change, Early Adaptation

\begin{abstract}
:
In Mongolia, from 1999 to 2001 and 2009 to 2010, about 10 million livestock animals were seriously died due to starvation and the cold by effects of overgrazing and Zud: extreme snow in winter season. Thus, it is required to reduce its risk by controlling number of overwinter livestock animals. In order to do that, it is required to simulate how many animals do herders have to sell followed by carrying capacity. In order to avoid climate risk, it is necessary to manage farming comprehensively and control livestock numbers. Nevertheless it needs to consider about management, we have to research information about each management under different conditions of each area in all Mongolia. Thus, it needs to survey livestock management workflows of regional administration and GIS data about rangeland areas and their attributes in order to evaluate their nomadic life and their livestock objectively. It is essential to use some tools that have the function of processing the spatial data. It could cover wide areas and have different abilities for spatial relations. To solve this problem; we analyzed management workflows of herder and regional administration working in Mongolia, and designed a hierarchical structure of tables and data layers with the relational database. With this structure, we developed the structure of a WebGIS tool on the Adobe Flex platform for livestock management visually. It will be also useful for them to improve the accountability of activities. This system is a versatile WebGIS tool which can interact with various spatial scales.
\end{abstract}

\section{INTRODUCTION}

In Mongolia, livestock animals were killed seriously by effects of climate change and it is required to reduce its risk by early adaptation. Selling livestock animals in unusual selling season is one of the early adaptation. Therefore, it is required to simulate when they need to sell their livestock animals and how many animals do herders have to sell. For getting these information, it is significant to evaluate carrying capacity in rangeland. Carrying capacity is different spatially due to relationship beween plant ecologies and livestock animals. Derry (1998, 2009) developed a model that it is possible to simulate carrying capacity. But his model has never been adapted to Mongolia case. In this study, we designed an early adaptation measure by estimating and managing carrying capacity, and evaluated their possibilities through researching databases and test results of simulation.

\section{METHOD}

\subsection{System for Livestock Animals Management}

As a system of early adaptation, it is significant to consider about how to manage carrying capacity. In our study, it is constructed from 3 steps. At first, developing a database for modeling. On second, running model and calculating carrying capacity by try and error. At last, developing a system of sending information to herders. In this study, first and second step was tested in small scale area in Mongolia, and evaluated possibility by their results.

\subsection{Database}

Mainly we used the phygrow data that is composed by Texas AM University and Mercy Corp (Angerer et al., 2009), which is
NGO, and they monitors many environmental conditions daily in 502 points in this area. There are also statistical data, GIS data and Physical Data of Animals. Thus it needs to make these data related in spatially by using geo-information systems, and interviewed to herders.

\subsection{System Design}

We analyzed free and national data sources in all Mongolia and designed a spatial structure of tables and data layers with the relational database. The structure of this system is shown in Figure.1. It was constructed in 3 layers, the bottom was Google Maps, the middle was GIS/RS data, the top was data created by users. In the middle layer, we used WMS (Web Mapping System) that was standardized by OGC (Open Geospatial Consortium). In the top layer, vector data were able to use by using Google Maps API. The data on the top layer were managed in MySQL, so users can update those data on the Google Maps interface by using Web browsers. and Mobile Phones. With this structure, we developed the WebGIS interface on the Adobe Flex platform..

\section{RESULTS FOR EVALUATING POSSIBILITY OF ADAPTATION DESIGN}

As a system of early adaptation, it is significant to consider about how to manage carrying capacity. In our study, it is constructed from 3 steps. At first, developing a database for modeling. On second, running model and calculating carrying capacity by try and error. At last, developing a system of sending information to herders. In this study, first and second step was tested in small scale area in Mongolia, and evaluated possibility by their results. 
Table 1. Data List for the System
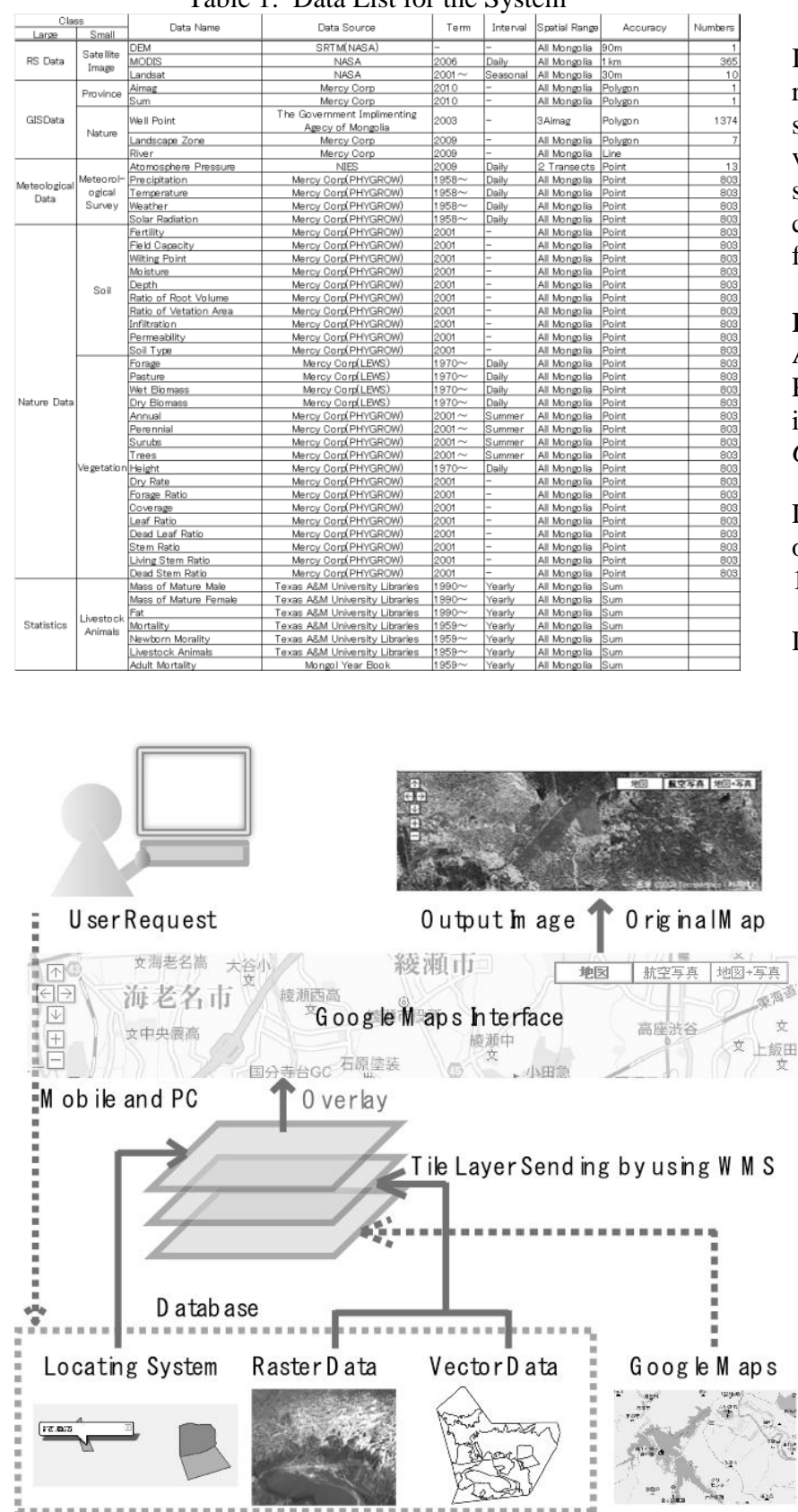

Figure 1. System Architecture

\section{CONCLUSION}

In this study, we made a design of early adaptation measures in response to climate change in Mongolia by 3 steps, and tested 2 steps. Test results showed positivly as the design, particularly vegetaion model was better from Angere et al.(2009), but also showed some subjects. For complete our design, we have to consider about other data sources and how to improve model for calculating livestock animals.

\section{References from Journal Articles}

Angerer, J., Sean, G., Doug, T. (2009) Technology Transfer Part I: Implementation of the Livestock Early Warning System in Mongolia. Global Livestock CRSP, Research Brief 09-01GOBI, Univ. of California-Davis.

Derry J.F. (1998) Modelling ecological interaction despite object-oriented modularity. Ecological Modelling, 107, 145158.

Derry J.F. (2009) Piospheres, Vdm Verlag, p.32 